\title{
RESEARCH ON THE INFLUENCE OF BLOWING AGENT ON SELECTED PROPERTIES OF EXTRUDED CELLULAR PRODUCTS
}

\author{
Tomasz Garbacz' , Tomasz Jachowicz'1, Ivan Gajdoš², Grzegorz Kijewski \\ 1 Department of Polymer Processing, Faculty of Mechanical Engineering, Lublin University of Technology, 36 \\ Nadbystrzycka St., 20-618 Lublin, Poland, e-mail: t.garbacz@pollub.pl, t.jachowicz@pollub.pl \\ 2 Technical University of Košice, Faculty of Mechanical Engineering, Institute of Technologies and Management, \\ Mäsiarska 74 Str., 04001 Košice, Slovakia, e-mail: ivan.gajdos@tuke.sk \\ 3 Student Scientific Circle of Polymer Processing, Faculty of Mechanical Engineering, Lublin University of \\ Technology, 36 Nadbystrzycka St., 20-618 Lublin, Poland, e-mail: g-kijewski@wp.pl
}

Received: 2015.09.21

Accepted: 2015.11.14

Published: 2015.12.04

\begin{abstract}
As a part of a more comprehensive research project, the present study was undertaken to investigate the effect of the type and content of blowing agents in the polymeric materials being processed on the structure and selected physical and mechanical properties of the obtained extrusion parts. In the experiment, the content of the blowing agent ( $0-2.0 \%$ by mass), fed into the processed polymer were adopted as a variable factor. In the studies presented in the article, the blowing agents of endothermic decomposition characteristics (Hydrocerol BIH 70, Hydrocerol BM 70) and the exothermic decomposition characteristics (PLC 751) occurring in the granulated form with a diameter of 1.2 to $1.8 \mathrm{~mm}$ were used. Based on the results of investigating porosity, porous structure image analysis as well as microscopic examination of the structure, it has been found that the favorable content of the blowing agent in the polymeric material should be of up to $0.8 \%$ by mass. With such a content of the blowing agent in the polymeric material, favorable strength properties are retained in porous parts, the pore distribution is uniform and the pores have similar sizes.
\end{abstract}

Keywords: thermoplastics polymers, cellular extrusion, blowing agents, mechanical properties.

\section{INTRODUCTION}

In recent years, cellular extrusion of polymers has been one of the fastest growing processing methods. It is used especially to obtain sections, bars, pipes and cellular coatings free from strains on the product surface, displaying reduced density and minimum shrinkage, at the same time, maintaining similar properties of products extruded in a conventional way. In the cellular extrusion process, porous structure is formed by mixing thermal decomposition products, chemical blowing agent with the material or inert gas brought to the plastic extrusion plasticizing in the system or directly into the formation $[1,2,3]$. Blowing agents (porophors) are a source of gas which diffuses into the polymer generates the pores. However, this does not mean that these additives must be in a form of gases - such as chemical blowing agents are often porous solids or liquids, which release gaseous substances only in a chemical reaction. For a porous material of appropriate structure and quality, the blowing agent has to be carefully selected, depending on processing conditions, type of polymer, and the assumed parameters of the final product $[2,4,5]$. The type and amount of added blowing agents have an effect on the final density of the porous material and to determine the choice of method of porous. In order to achieve a high degree of the so-called physical blowing agents (gases, volatile liquids) are used. Chemical blowing agents are 
applied where it is necessary to maintain low levels of capital expenditures on equipment and machinery $[3,6,7]$. The essence of this process is the introduction of the plastic material (support), the most are concentrated (5-70\% concentration) or powders. The difference between the process of physical and chemical materials blowing agents is less associated with the course of the process, while more important is the dosing of blowing agents to polymers $[4,8,9]$.

Properly selected processing conditions make it possible to manufacture products with new, modified physical and technological properties. The new products are characterized, among others, by reduced weight, improved damping and insulation properties and the possibility of utilization after use, retaining at the same time physical and technological properties similar or identical to those of cellular products (Fig. 1). To obtain cellular structure, the properties of an products are modified by using an appropriate type of polymer or by incorporating blowing agents (porophors) into the polymer.

Modification of cable coatings and research on the extrusion process conducted in the Department of Polymer Processing at Lublin University of Technology [3-11] are focused especially on manufacturing coatings from cellular plastics, what results in the reduction of plastic purchase costs, energy costs of the process and transportation costs. At the same time, this results in the replacement of conventional extrusion coating by the cellular extrusion process [11-14]. The obtained extruder product may have a fully solid or cellular structure, it may be cellular in its entirety, or have a cellular core and a solid topcoat (Fig. 2).

Blowing agents used in cellular extrusion of plastics may show exothermic or endothermic decomposition characteristics. Porophors used to date usually present exothermic decomposition characteristics. This may be the cause of local overheating and generation of irregular cellular structure of the product $[8,9,15]$. The initiated porophor decomposition process progresses automatically even after energy cut-off. Therefore, products extruded with the use of such agents must be intensely cooled for a long time, in order to prevent strains and keep proper cellular structure. The main representatives of this group include hydrazides, e.g. sulfohydrazide and azo compounds, for instance azodicarbamide. This compound is widely used in microcellular extrusion of polyethylene, polyvinyl chlorine, polystyrene and polyamide $[3,5,7,12,13,17]$.
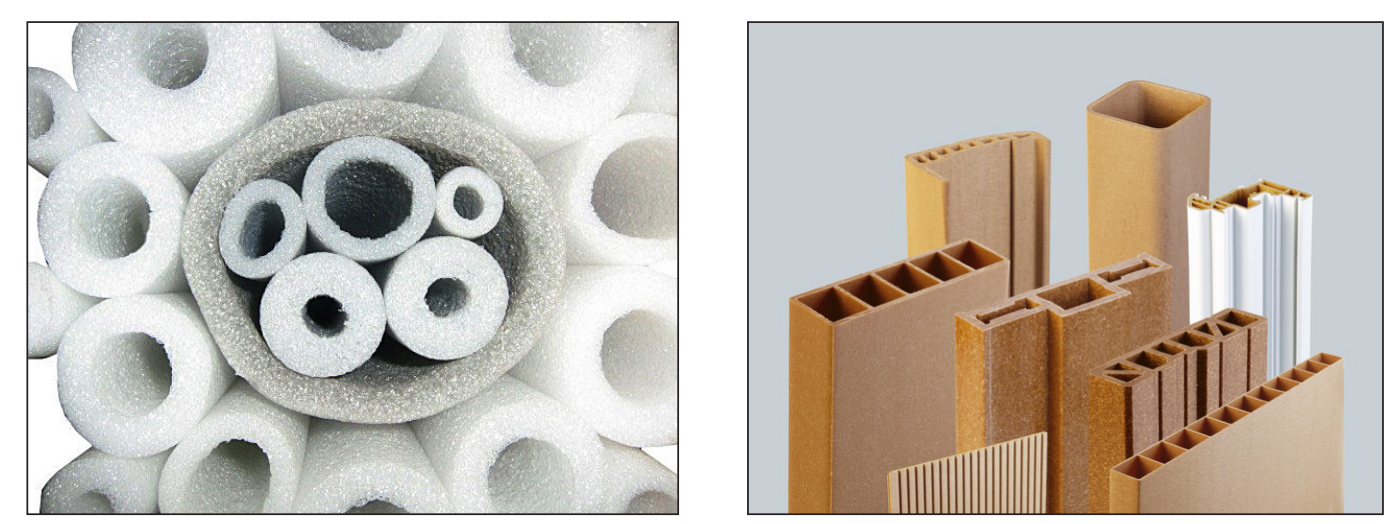

Fig. 1. Example of cellular products made in extrusion process [20]
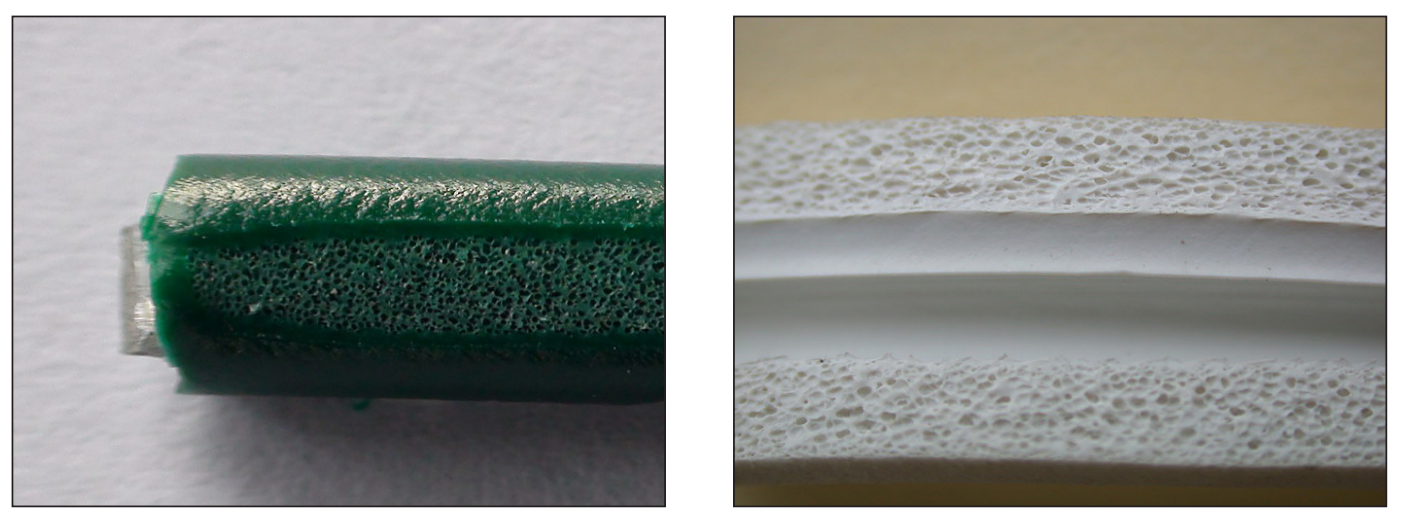

Fig. 2. View of the porous structure of cellular coating obtained in the extrusion process using chemical blowing agents 
In the case of blowing agents with endothermic decomposition characteristics, generation of gas during processing is rapidly stopped when the energy flow is cut off. Application of such blowing agents considerably shortens cooling time. The aim of the conducted research was to discover the influence of modifying thermoplastic polymers (PE, PP and PVC) with selected agents, that is a blowing agent, in the course of the extrusion process, inclusive of determination how the modification affects selected physical properties and the structure of extrusion product.

\section{EXPERIMENTAL PROCEDURE}

Three thermoplastics were used in the experiments. The first one was polypropylene PP, marketed under the trade name Malen P-S901. According to the data provided by the manufacturer, the thermoplastic has a density of $900 \mathrm{~kg} / \mathrm{m}^{3}$, melt flow rate (MFR) of $2.5-3.5 \mathrm{~g} / 10 \mathrm{~min}\left(230{ }^{\circ} \mathrm{C}\right.$; $2.16 \mathrm{~kg}$ ), and tensile stress at yield of $25 \mathrm{MPa}$. Another polymeric material used in the experiments was polyethylene LDPE, marketed under the trade name Malen E, FABS 23-DO22, with a density of $925 \mathrm{~kg} / \mathrm{m}^{3}$, MFR range $1.6-2.5 \mathrm{~g} / 10$ $\min \left(190{ }^{\circ} \mathrm{C} ; 2.16 \mathrm{~kg}\right)$, tensile stress at yield of 12 MPa. The third polymer used in the experiments was poly(vinyl) chloride PVC, marketed under the trade name Alfavinyl - GFM/4-31-TR, with a density of $1230 \mathrm{~kg} / \mathrm{m}^{3}$ and tensile stress at yield of $21 \mathrm{MPa}$, according to the data provided by the manufacturer.

The abovementioned plastic was modified with a physical blowing agent with endothermic decomposition characteristics, taking a form of a blowing system. This agent was delivered as $0 \% ; 0.4 \% ; 0.8 \%$ and $2.0 \%$ of the mass. In the experiments, three types of chemical blowing agents were used: Hydrocerol BIH 70, Hydroc- erol BM70 and Hydrocerol PLC 751, both manufactured by Clariant Masterbatches $\mathrm{GmbH}$. The blowing agents, with their trade names BIH 70 and $\mathrm{BM} 70$, have the characteristics of endothermic decomposition. Hydrocerol PLC 751 is a blowing system with exothermic decomposition characteristics, taking a form of granules ranging from 1.5 to $1.6 \mathrm{~mm}$ in diameter. Hydrocerol PLC 751 contains $50 \%$ of the mass of the blowing agent with initial decomposition temperature of $170{ }^{\circ} \mathrm{C}$. Hydrocerol BIH 70 is a blowing system with endothermic decomposition characteristics, taking a form of granules ranging from 1.2 to 1.8 $\mathrm{mm}$ in diameter. Hydrocerol $\mathrm{BIH} 70$ contains $70 \%$ of the mass of the blowing agent with initial decomposition temperature of $140{ }^{\circ} \mathrm{C}$. In the presented research, Hydrocerol PLC 751 and Hydrocerol $\mathrm{BIH} 70$ were dispensed as $0.2 \%$ to $0.8 \%$ of the mass.

The extruding process was carried out with the use of a single-screw extruder, type W-25 with the screw diameter of $\mathrm{D}=25 \mathrm{~mm}$. The plasticizing unit was equipped with four heating zones. The process line was composed of the extrusion coating head, vacuum calibrator, the cooling bath and the remaining process line components. The plasticizing unit was equipped with four heating zones. The process line was composed of the extrusion head, the cooling bath and the remaining process line components. Extrusion was carried out under the following parameters: temperature of the heating zones $150,160,160$ and $165^{\circ} \mathrm{C}$ respectively; extruder head temperature within two heating zones $155^{\circ} \mathrm{C}$.

As a result of the carried out process of extruding PE, PP and PVC modified with blowing agents, the extruder product was obtained in a form of a pipe of $10.00 \pm 0.01 \mathrm{~mm}$ in diameter. Extrusion and cooling conditions were properly selected, which allowed to obtain a product having a solid topcoat and a cellular core (Fig. 4).
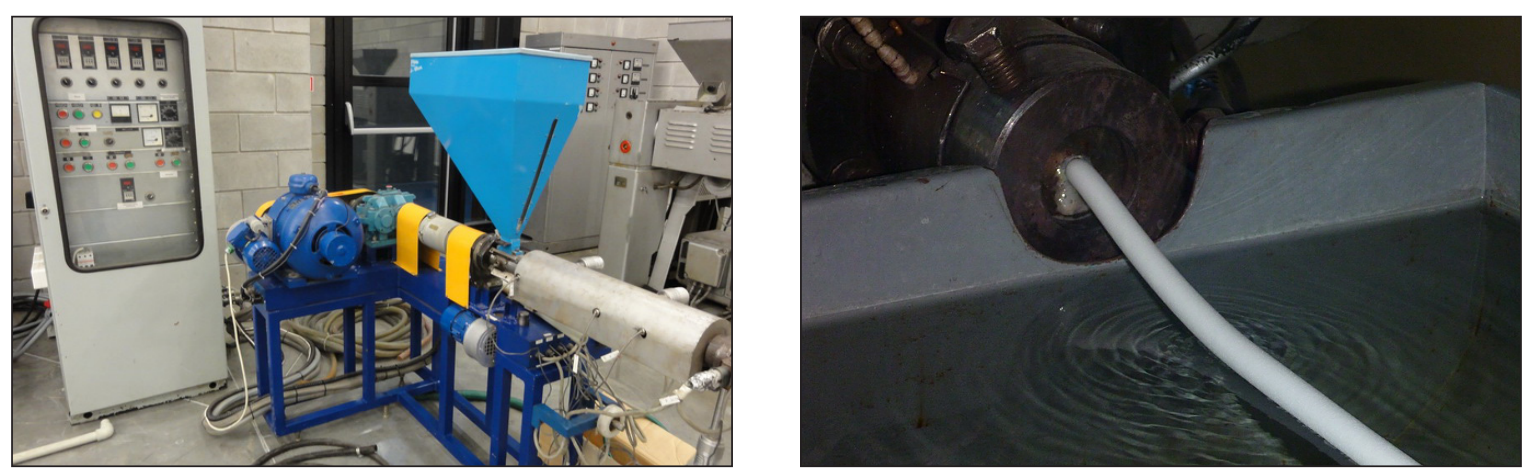

Fig. 3. View of the technological line section for extrusion process and extruded product 

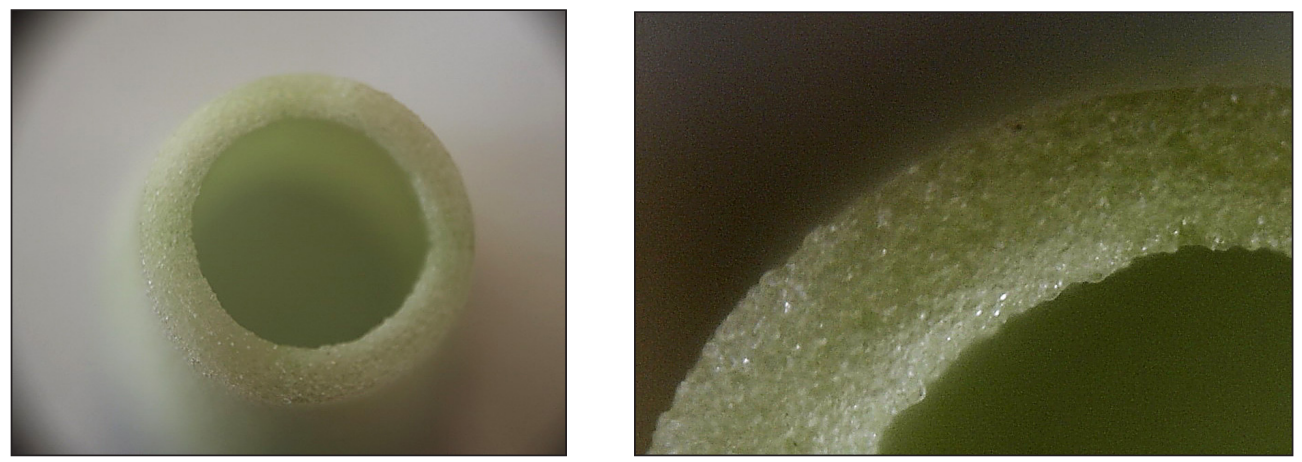

Fig. 4. View of the porous structure obtained in the cellular extrusion process of pipe

In order to determine selected mechanical properties of the extrusion parts, both hardness tests using Shore's method and tests for tensile strength, yield point and elongation at break were conducted, in accordance with the relevant norms (PN-EN ISO 868 (2003) and PN-EN ISO 527-1 (2010) $[18,19]$. The applied shape and dimensions of the specimens complied with the relevant norm. The specimen thickness corresponded to the extrusion part thickness and it was measured and registered each time together with the width of the measuring length, right before the tests.

Strength properties of the extrusion parts under static tension were determined using a testing machine manufactured by Zwick Z010. The machine was equipped with $10 \mathrm{kN}$ screw wedge chucks together with the accessories. The measurements were done at a tensile speed of $10 \mathrm{~mm} /$ min and under the measuring load range $0-500 \mathrm{~N}$. The hardness tests by Shore's method were conducted using an Affri-manufactured hardness tester, type ART13 - Shore's method D. Such choice was due to the employed method for determining the hardness of solid polymers.

The investigation and analysis of the porous structure of the produced extrusion parts were conducted using an confocal microscope, type Olympus FluoView FV1000 and copyright posi- tion of image analysis of porous structure and the author's stand for porous structure image analysis. Microscope FV1000 equipped with 1.3 MPix camera, enabling direct viewing of microscaning image in a computer screen. Observations of specimens structure and its recording were made in reflected light with suitable magnification.

The porous structure image analysis is used to determine geometric characteristics of pores based on the images of porous structure taken. The images are taken using an optical camera with an electronic amplifying system and then analyzed in a computer stand equipped with special graphics software. The stand for porous structure image analysis is shown in Figure 5.

\section{RESULTS AND DISCUSSION}

The results of determining selected strength properties of the extrusion parts, obtained at different contents of the blowing agent in the polymers being processed, are shown at Figures 6-10. The results of hardness of the extrusion parts are graphically represented at Figures 6-7. The type of a blowing agent used, be it with the endothermic or exothermic decomposition characteristics, has no effect on the surface hardness of the extru-
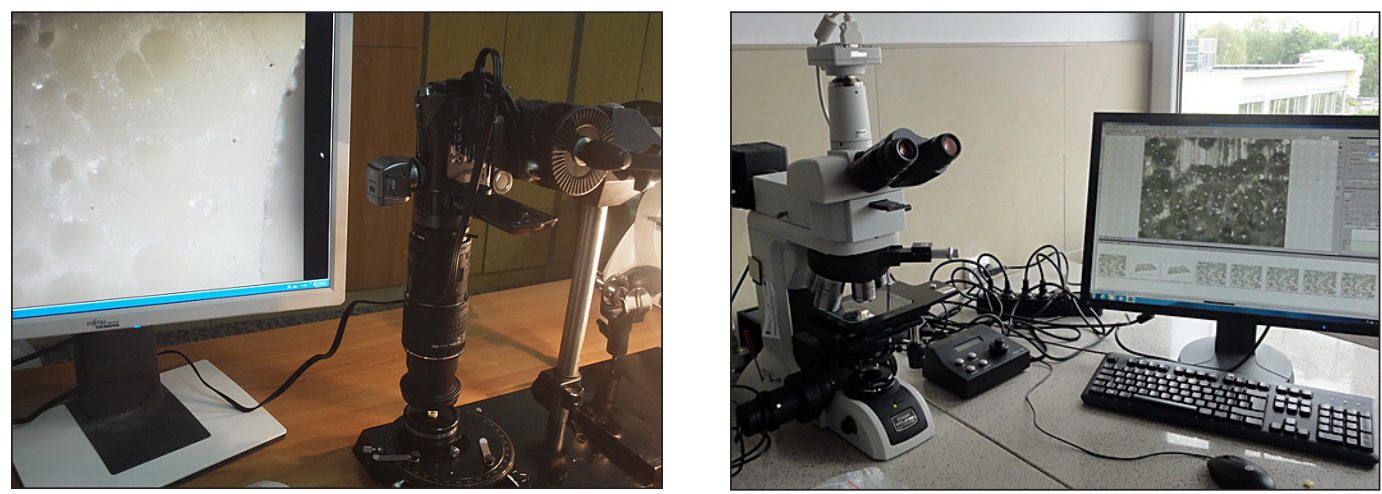

Fig. 5. Author's stand for porous structure image analysis and Olympus FluoView FV1000 stand 


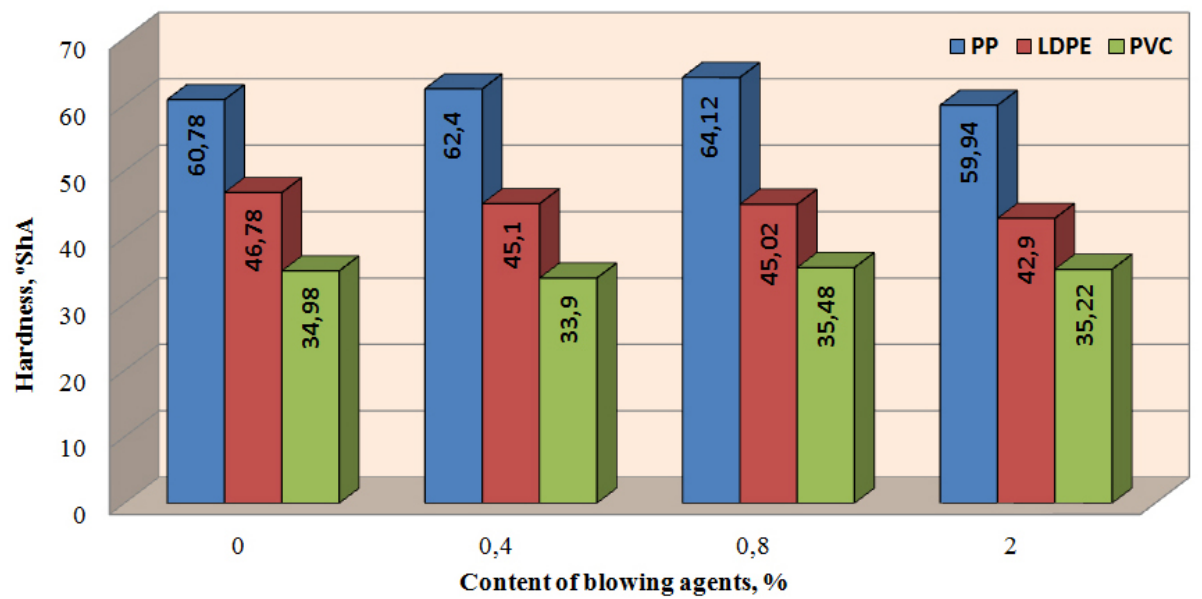

Fig. 6. Dependence of Shore D hardness of extruded parts on the content of blowing agent Hydrocerol BM 70

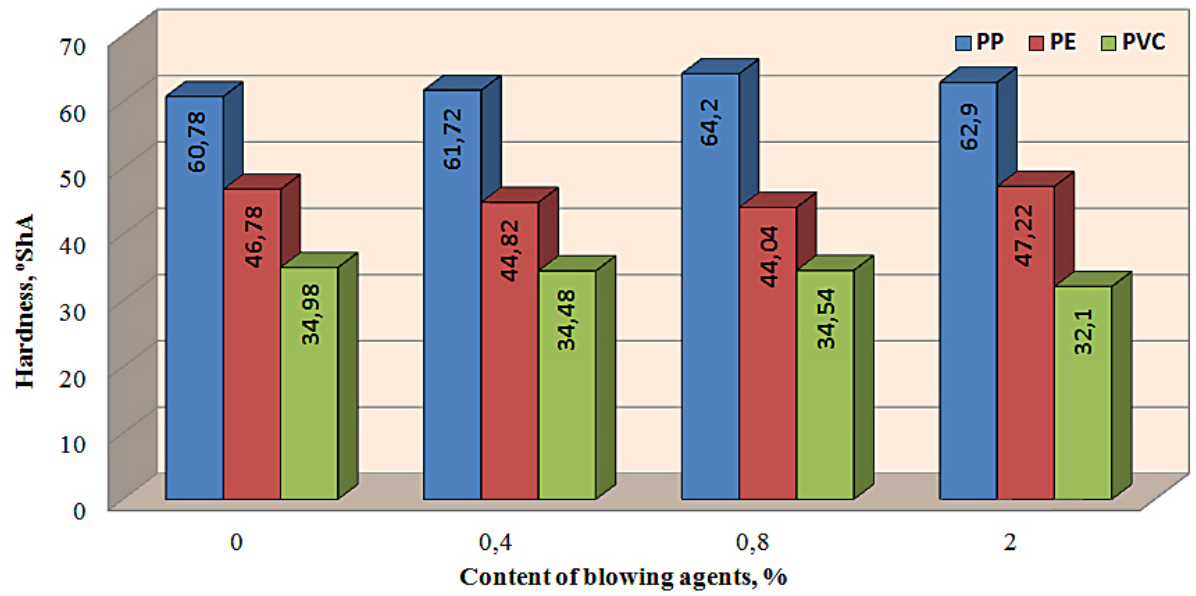

Fig. 7. Dependence of Shore D hardness of extruded parts on the content of blowing agent Hydrocerol PLC 751

sion parts. The changes in hardness illustrated in the figures predominantly depend on the type and properties of the polymeric materials used in the cellular extrusion process.

The results of the tensile strength tests of the specimens made from the polymers modified by the blowing agents correspond to the results of the conducted hardness tests. The extrusion parts made from porous polymers have decreased mechanical properties, strength properties included (Fig. 8-10). It has been observed that increasing the blowing agent content in the product decreases the value of tensile strength in a nonlinear manner in the whole content range of the blowing agent in the polymer. The distribution of the curves demonstrates that at high content of the blowing agent (over $0.8 \%$ ) in the polymer, the intensity of the decrease in tensile strength is lower, irrespective of the type of the polymer being processed and the type of the blowing agent used. The intensity of stress reduction is higher when the blowing agent content ranges from 0.8 to $2.0 \%$ of the mass in relation to the mass of the plastic. The ultimate elongation is reduced more intensely with lower blowing agent content ranging from 0 to $0,4 \%$ of the mass.

Significant differences in mechanical strength of the cellular extrusion parts can be observed. For example, the blowing agent Hydrocerol BIH 70 , with the endothermic decomposition characteristics, dosed in the range from 0 to $2.0 \%$ causes a decrease in tensile strength by $24 \%$ on average in the case of polypropylene (Fig. 8), by $21 \%$ when fed into PE, and by $35 \%$ in the case of PVC (Fig. 9-10). When the blowing agent with the exothermic decomposition characteristics is used (Hydrocerol PLC 751), the change in tensile strength is more considerable and it has the following values: $\mathrm{PP}-25 \%, \mathrm{PE}-27 \%$, and in the case of PVC $-30 \%$, as illustrated in figures $8-10$.

The change in tensile strength for the polypropylene molded parts, graphically represented in figure 8 , differs from the distributions for polyethylene and poly(vinyl) chloride. Significant differ- 


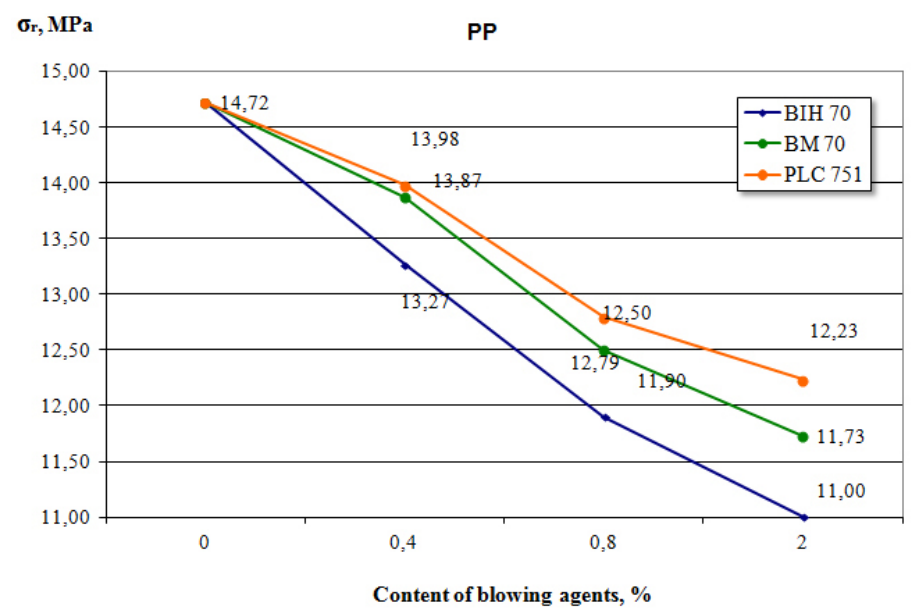

Fig. 8. Dependence of tensile strength of PP extrusion parts on the content of Hydrocerol BIH 70, Hydrocerol BM 70 and PLC 751

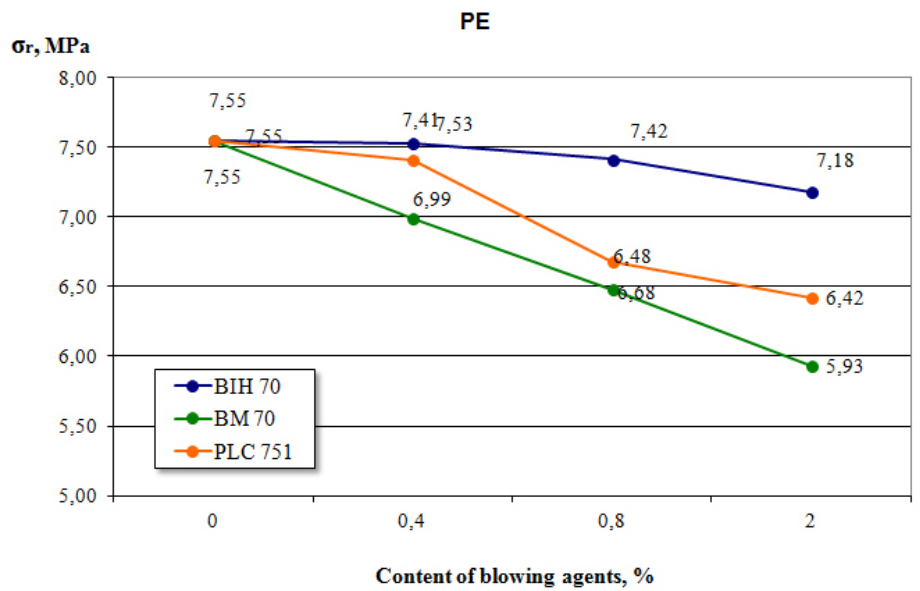

Fig. 9. Dependence of tensile strength of PE extrusion parts on the content of Hydrocerol BIH 70, Hydrocerol BM 70 and PLC 751

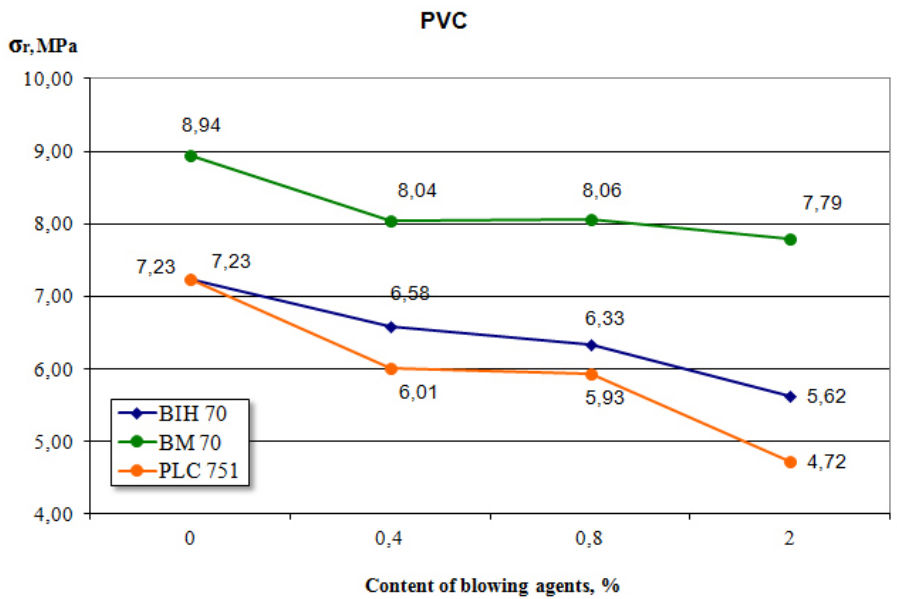

Fig. 10. Dependence of tensile strength of PVC extrusion parts on the content of Hydrocerol BIH 70, Hydrocerol BM 70 and PLC 751

ences in the value of change in mechanical strength of the extrusion parts can be observed. The blowing agent, dosed in the amount of $2 \%$, irrespective of the characteristics of its effect, causes a substantial worsening of strength properties.
The macroscopic structure of the produced cellular products was examined at the stand for polymer cellular structure image analysis. The examples of the cellular structure of coatings produced are shown in figures 11,12 and 13. 

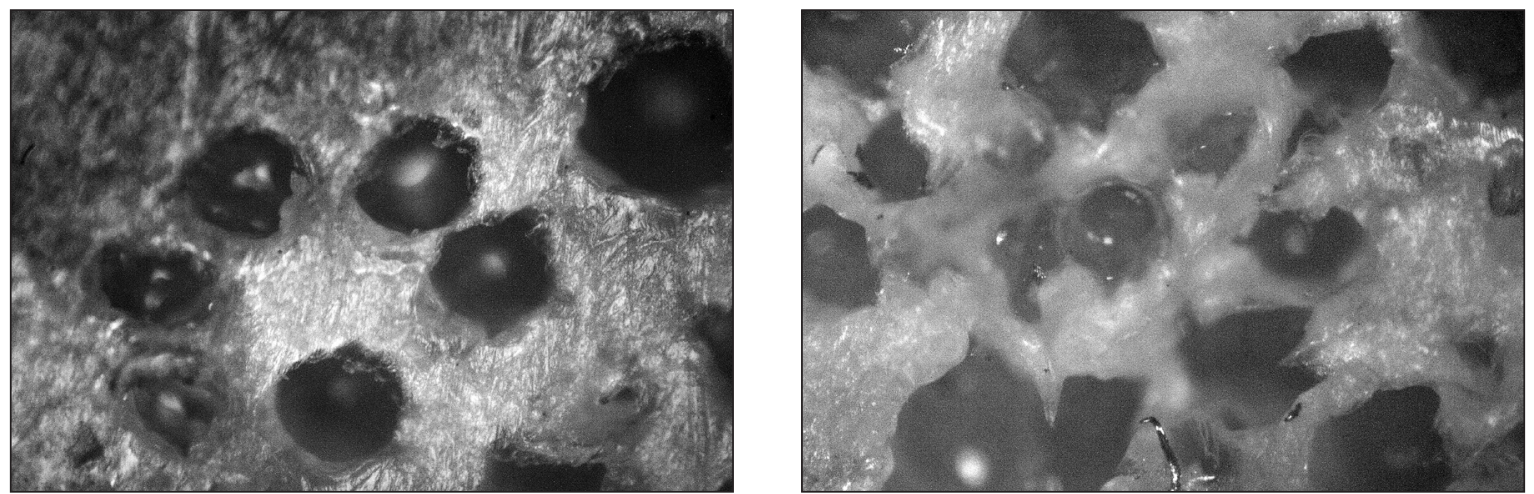

Fig. 11. Cross section of a cellular PE product with $0.4 \%$ and $2.0 \%$ mass. content of the blowing agent Hydrocerol PLC 751, magnify 50×
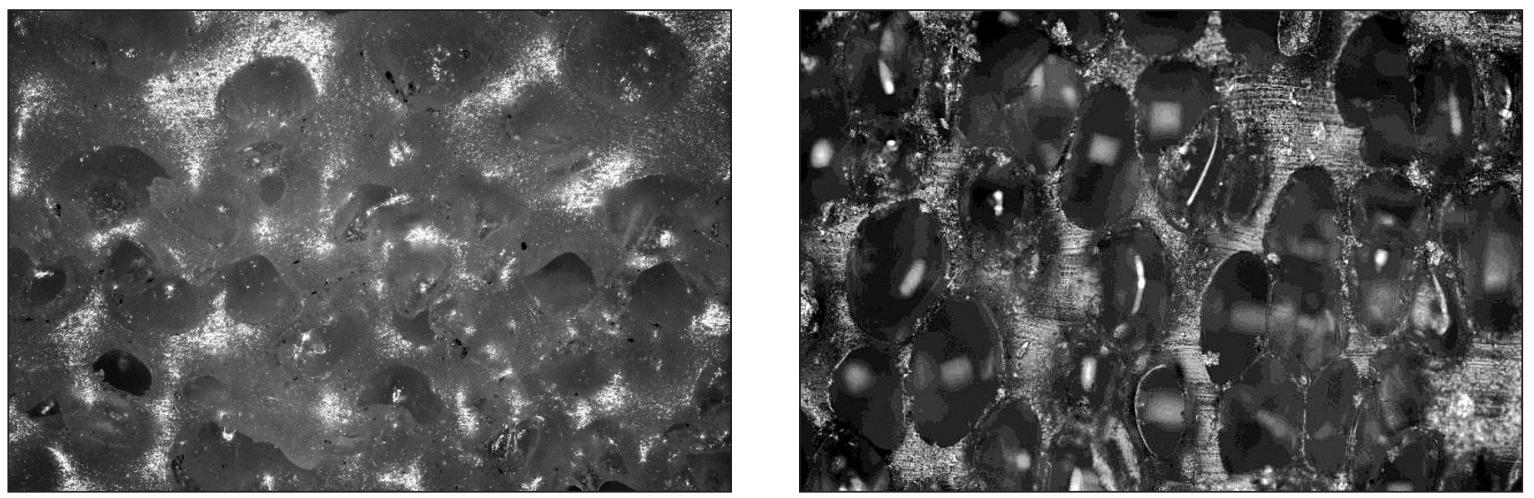

Fig. 12. Microscopic image of the cross section of a cellular PVC product with $0.4 \%$ content of the blowing agent Hydrocerol BM 70 and with $2.0 \%$ content of the PLC 751 , magnify $50 \times$
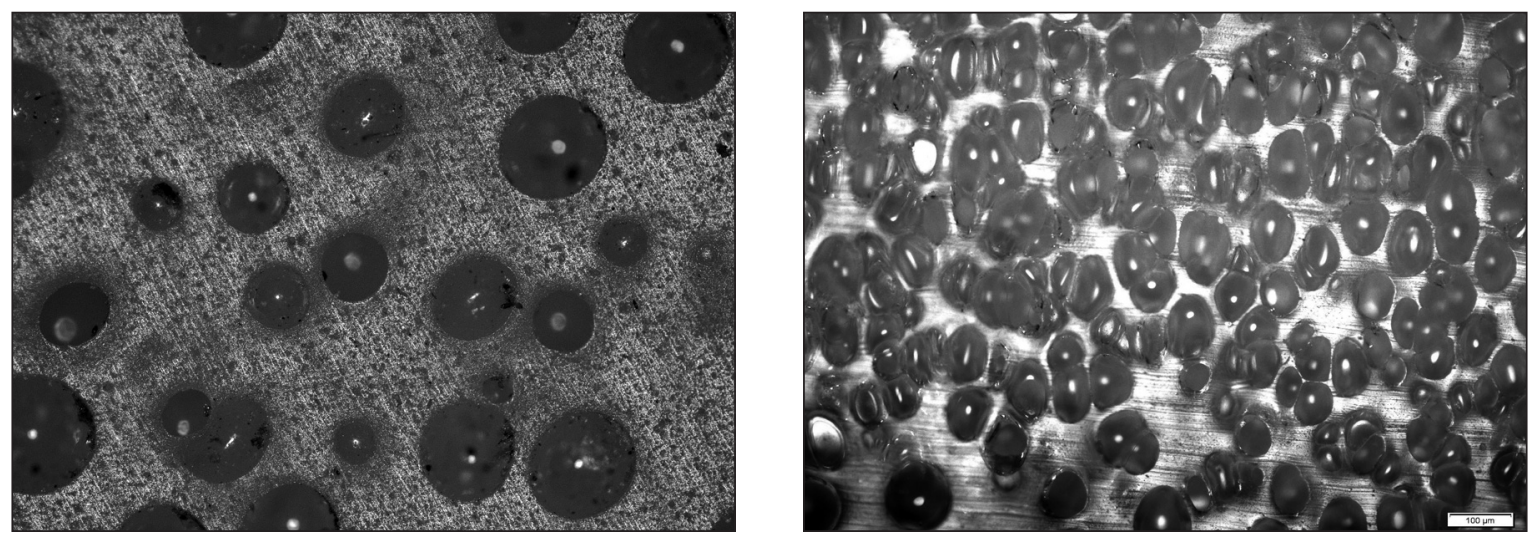

Fig. 13. Microscopic image of the cross section of a cellular PP product with $0.4 \%$ content of the blowing agent Hydrocerol BIH 70 and with $0.8 \%$ content of the PLC 751 , magnify $50 \times$

Extrusion products made of PE with $0.4-0.8 \%$ blowing agent content do not have sufficiently cellular structure (Fig. 11). The cell dispersion patterns in the structure could be attributed to the non-uniform dosing of a very small blowing agent amount into the polymer and the characteristics of the applied blowing agent with the endothermic decomposition behavior. Based on the analysis of the photographs taken, it can be seen that the pipe with the 0,8 and $2,0 \%$ blowing agent contents has a visible solid surface and most uniform distri- bution of similarly sized pores. The numbers of pores increases proportionately to the increase in the blowing agent content in the extruded polymer. The number of pores also depends on their position and distance from the surface.

\section{CONCLUSIONS}

Blowing agents used in the cellular extrusion process give a possibility of creating products 
with new, modified properties, without causing important changes. Changes in these properties offer new possibilities of applying this kind of products with simultaneous reduction in their production costs. The use of a blowing agent with endothermic decomposition characteristic dispensed from 0,4 to $2,0 \%$ of the mass, allows to obtain a product that meets the expectations and objectives of the conducted research.

Strength properties, hardness and tensile strength discussed in the paper depend, to a great extent, also on the characteristics of the blowing agent used. This is largely due to thermal properties of the polymeric materials used and the effect of the blowing agents on the polymeric materials used in the process. However, such dependence has not been thoroughly investigated yet and will therefore be a subject of further studies.

Owing to the application of the blowing agent with the exothermic decomposition characteristics (Hydrocerol PLC 751 system), a more cellular part, with a higher number of pores is produced. The initiated decomposition of the exothermic agent happens in an uncontrolled manner, even after the power supply is shut off. For this reason, parts produced with such blowing agents often have a non-uniform porous structure. In the case of porous parts produced using the blowing agents with the endothermic decomposition characteristics, the gas release in the course of processing ends once the energy supply is over (BIH 70 , BM 70). The obtained porous structure is uniform, the pores have a spherical or quasi spherical shape. The pores are of similar sizes, irrespective of their location in the product.

\section{REFERENCES}

1. Okamoto K.T.: Microcellular processing. Hanser Publishers, Munich, Germany 2003.

2. Sikora J.W.: Screw extrusion. In: Sabu T. Yang (Ed.) Advances in polymer processing. From macro to nanoscales. Woodhead Publishing Limited. OxfordCambridge-New Delhi, United Kingdom 2009.

3. Garbacz T.: Properties of triple-layered PVC coatings synthesized in the micropore coextrusion method. Polimery 56, 7-8, 2011, 129-134.

4. Samujło, B., Sikora, J.W.: The impact of selected granulometric properties of poly(vinyl chloride) on the effectiveness of the extrusion process. Journal of Polymer Engineering 33, 1, 2013, 77-85.

5. Tor-Świątek A., Samujło B.: Use of thermovision research to analyze the thermal stability of micro- cellular extrusion process of poly(vinyl chloride). Maintenance and Reliability 15, 2013, 58-61.

6. Garbacz T., Dulebova L.: Porophors during the extrusion process. Chemistry and Chemical Technology $7,1,2013,113-118$.

7. Garbacz T., Tor A: Effect of porophor content on the useful properties of external coatings of cables obtained by foaming extrusion. Polimery 52 , 2007, 286-293.

8. Garbacz T.: Cellular process of polymer material. Management and control of manufacturing processes. Lubelskie Towarzystwo Naukowe. Lublin 2011, 125-130.

9. Tor-Świątek A.: Evaluation of the effectiveness of the microcellular extrusion process of low density polyethylene. Maintenance and Reliability 15, 3, 2013, 225-229.

10. Garbacz T., Dulebova L.: Calibration process and constructions of extrusion calibrations. Key Engineering Materials 635, 2015, 135-138.

11. Garbacz T.: Structure and properties of cellular thin-walled cable coatings, Polimery 57, 11-12, 2012, 91-94.

12. Martial S., Jacques F., Audrey C., Clémence N., Rodier E.: New challenges in polymer foaming: A review of extrusion processes assisted by supercritical carbon dioxide. Progress in Polymer Science 2011, 36, 749-766.

13. Urbanczyk L., Alexandre M., Detrembleur Ch.: Extrusion foaming of poly(styrene-coacrylonitrile)/Clay nanocomposites using supercritical $\mathrm{CO}_{2}$. Macromolecural Material Engenering, 295, 2010, 915-922.

14. Sikora J.W., Samujło B., Dzwonkowski J.: Influence of a feed-opening section on the output and selected mechanical properties of a poly(vinyl chloride) extrudate. Advances in Polymer Technology 33, 1, 2014 (published online).

15. Guo M.C., Heuzey M.C., Carreau P.J.: Cell structure and dynamic properties of injection molded polypropylene foams. Polymer Engineering and Science 47, 2007, 1070-1081.

16. Zhou Q., Chuan-Bo C.: Exo-endothermic blowing agent and its blowing behavior. Journal of Cellular Plastics 41, 2005, 225-234.

17. Bociąga E., Palutkiewicz P.: The impact of mould temperature and blowing agent content on structure and properties of injection moulded parts. Cellular Polymers 32, 5, 2013, 257-277.

18. PN-EN ISO 868 (2003): Plastics and ebonite. Determination of indentation hardness by means of a durometer (Shore hardness).

19. PN-EN ISO 527-1 (2010): Plastics. Determination of tensile properties.

20. Websites: www.maisplastico.com.br, www.greinerextrusiontechnik.com 